http://jmscr.igmpublication.org/home/ ISSN (e)-2347-176x ISSN (p) 2455-0450 crossref DOI: https://dx.doi.org/10.18535/jmscr/v8i3.22

\title{
A Study of the Tributaries of the Coronary Sinus
}

\author{
Authors \\ Dr Pusphakala $K^{1}$, Dr Vidulatha $K^{2}$ \\ ${ }^{1,2}$ Assistant professor of Anatomy, Institute of Anatomy, Madurai Medical College, Madura \\ *Corresponding Author \\ Dr K. Vidulatha
}

Assistant Professor of Anatomy, Institute of Anatomy, Madurai Medical College, Madurai Tamilnadu, India

\begin{abstract}
Introduction: The largest vein of the heart, the coronary sinus also acts as a gateway to the epicardium of the left ventricle. The venous system of the heart are often overshadowed by the presence of the arteries of the heart. The venous trunk extending from the vieussens valve to the coronary sinus ostium in the right atrium is called as coronary sinus. It is about 2-3 cms long. A tremendous increase in the electrophysiological procedures and transvenous implantations warrant a complete knowledge of the coronary venous system and its tributaries.
\end{abstract}

Materials and Methods: About 50 adult human hearts were studied, which were obtained from the cadavers of the Institute of Anatomy, Madurai medical college, Madurai.(over a period of 3 years) They were dissected and the formation, course, tributaries and termination of the coronary sinus were studied in the specimens.

Result: The great cardiac vein and the middle cardiac vein were present in all the specimens. Small cardiac vein was present in $96 \%$ of the specimens and was absent in $4 \%$ of the specimens.

Conclusion: The utmost important vein of the heart is the coronary sinus. The tributaries of the coronary sinus are Great cardiac vein, middle cardiac vein, small cardiac vein, posterior vein of the left ventricle and oblique vein of the left atrium. The complete knowledge of the anatomy of the coronary sinus and its tributaries are of great importance in the field of interventional cardiology.

Keywords: Great cardiac vein, oblique vein of Marshall, coronary ostium, middle cardiac vein, interventricular septum.

\section{Introduction}

The coronary sinus is a large, wide venous trunk which drains the major portions of the heart. It is in the posterior portion of the atrioventricular groove. ${ }^{3}$ The coronary sinus is usually considered to be the continuation of the great cardiac vein distal to its junction with the oblique vein. ${ }^{2}$ This junction is guarded by a valve called Vieussens valve $^{1}$.

\section{Tributaries of Coronary Sinus (CS)}

\section{Great cardiac vein (GCV)}

It starts from the cardiac apex, runs upwards in the anterior interventricular sulcus to the left end of the coronary sulcus, where it continues as coronary sinus. ${ }^{23}$ Its tributaries are vein of the left atrium and both the ventricles. The orifice of GCV is covered by vieussens valve. ${ }^{1}$ 


\section{Small cardiac vein (SCV)}

SCV has the greatest course and opening variability. It is located in the posterior atrioventricular groove between right atrium and ventricle and opens at the right end of the sinus. In most of people it lies in the posterior part of coronary sulcus along with right coronary artery. The SCV commonly drains into the CS at its right end, or it may drain in to MCV, or it may form a common trunk with MCV and then drain into CS. Rarely it drain into right atrium directly. It receives tributaries from right atrium, right auricle and right ventricle. ${ }^{1,5,6}$

\section{Middle cardiac vein (MCV)}

It begins from the cardiac apex, passes along the posterior interventricular groove and terminates at the right end of sinus. Rarely it terminates into the right atrium directly. It is also called as posterior interventricular vein, is the largest proximal tributary of CS and receives tributaries from the interventricular septum and from both ventricles. $^{1,3,5,6}$

\section{Posterior vein of left ventricle (PVLV)}

It is present a small distance to the left of MCV and takes upward course with the posterior ventricular artery which is a branch of left circumflex artery. It drains the inferior surface of left ventricle that opens into the middle of CS but sometimes into the great cardiac vein. ${ }^{1,2,7}$

\section{Oblique vein of the left atrium (OVLA)}

It is called as Marshall Vein which is a remnant of left superior vena cava lies on the posterior surface of left atrium and anterior to the left inferior pulmonary vein opening. This small vein drains the posterior aspect of left atrium. ${ }^{18}$

\section{Embryology of Coronary Sinus}

Coronary sinus is formed by the persistent small channel proximal part of the left common cardinal vein, where most of the coronary veins empty. ${ }^{8}$ Around tenth week of development the distal part of the left common cardinal vein degenerates. ${ }^{6}$
The remaining part of the left horn of sinus venosus becomes the oblique vein of the left atrium. The right horn incorporated into the right atrium to form smooth portion of the right atrium. $^{22}$

The sinoatrial orifice has right and left venous valves. The left venous valve and the septum spurium fuse with the developing atrial septum. The superior part of right venous valve disappears, the inferior part develops into two parts, the valve of the coronary sinus and the valve of the inferior venacava ${ }^{9}$.

\section{Materials and Methods}

Over a period of 3 years, 50 formalin fixed human cadaveric hearts were dissected and studied in the Institute of Anatomy, Madurai medical college, Madurai. A complete study of coronary sinus and its tributaries were conducted and the results were tabulated.

\section{Observations}

- Great cardiac vein was present in all specimens and all of which drained into the coronary sinus.

- Middle cardiac vein was present in all specimens, of which $92 \%$ directly drained into coronary sinus, $6 \%$ formed a common trunk with small cardiac vein and then drained into CS, $2 \%$ directly drained into right atrium

- Small Cardiac Vein was present in $96 \%$ of specimens and absent in $4 \%$ of specimens.

- The Small Cardiac Vein was two in number in $2.1 \%$ of specimens and it was one in number in $97.9 \%$ of specimens. It drained into CS in $70.8 \%$ of heart specimens, and formed common trunk with Middle Cardiac Vein in $6.3 \%$ of specimens and drained into the Middle Cardiac Vein in $22.9 \%$ of specimens.

- The posterior vein of left ventricle was one in number in $60 \%$ of specimens, double in $34 \%$ of specimens, triple vein in $4 \%$ of specimens and five veins in $2 \%$ of specimens. 
- The posterior vein of left ventricle was drained into Coronary Sinus in $98 \%$ of specimens and in $2 \%$ of specimens drained into the Great Cardiac Vein.

- Oblique vein of Marshall was present in all fifty specimens, all of which drained into Coronary Sinus at its left end.

- Marginal vein of left ventricle was present in all fifty heart specimens and single in $98 \%$ of specimens, and double in number in $2 \%$ of specimens. Marginal vein of left ventricle opened into Great Cardiac Vein in $90 \%$ of specimens and in $10 \%$ of specimens drained into Coronary Sinus.

- The circumflex branch of left coronary artery runs superficial to the Coronary Sinus in $2 \%$ of specimens, deep in $88 \%$ of specimens, above in $8 \%$ of specimens and below in $2 \%$ of specimens.

- The Coronary Sinus lies above the Mitral valve annulus in all fifty heart specimens.

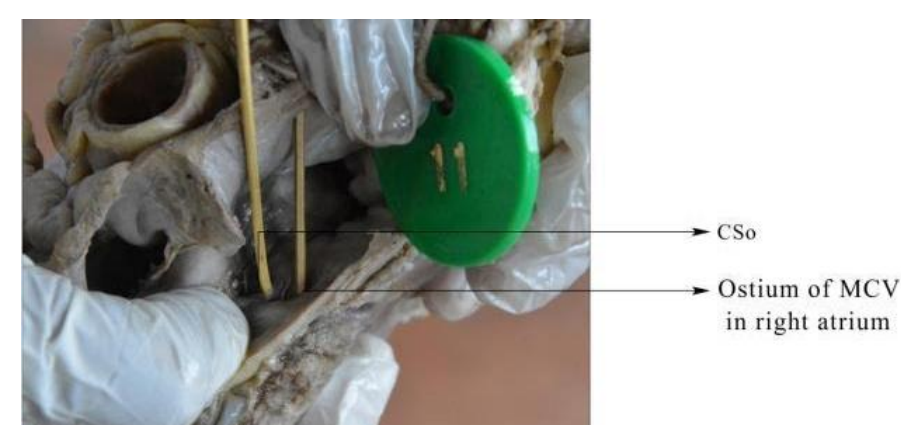

Figure 1. MCV draining directly into right atrium

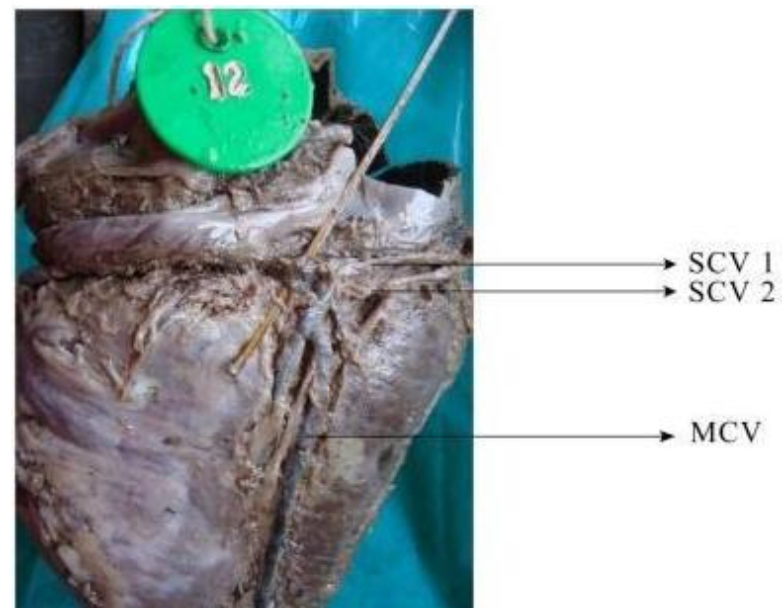

Figure 1. Double small cardiac vein

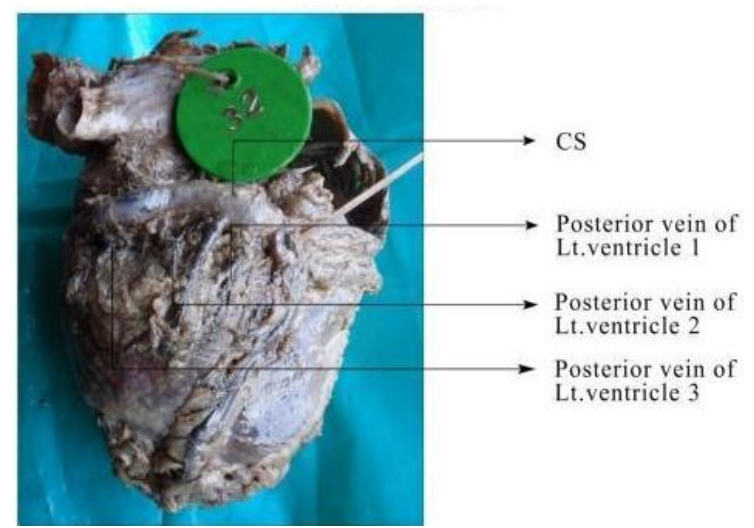

Figure 3. Triple posterior vein of left ventricle

\section{Discussion}

1) Von Ludinghausen ${ }^{15}$ reported a single case in which GCV joined with anterior cardiac vein that opened into the right atrium.

2) Praveen $B^{16}$ found in his study, that in one case the GCV drained directly into the right atrium without joining any other veins and it received normal tributaries from left atrium and both ventricle. The CS was normal.

3) The small cardiac vein was present in $46 \%$ of specimens in Adachi study, 94\% of specimens in Ratajczyk-pakalska, 54\% of specimens in ortale ${ }^{11}$ Study, $46 \%$ of specimens in Jongbloed, on the current study SCV was present in $96 \%$ specimens.

4) Malgorzata Mazur ${ }^{13}$ et al stated in his study that SCV present in all specimens and all drained in to the CS directly.

\section{d) Variations of oblique vein of left atrium}

1) Adachi (1933) stated in his study that OVLA present in $98 \%$ of specimens.

2) According to Monika cerdrowska pinkoz $^{10}$, by corrosion casting technique the oblique vein was present in $97 \%$ and in $3 \%$ it was not present.

3) According to oliveira ${ }^{18}$ et al the oblique vein was present in $87 \%$ of heart specimens and was absent in $13 \%$ specimens.

4) In Malgorzata Mazur ${ }^{13}$ corrosion casting study he found the oblique vein in $97.5 \%$ of specimens, all drained in to CS except 
one specimen which drained in to the GCV.

\section{e) Posterior Vein of Left Ventricle}

In De Valle-Fernandez et al study he stated that in $10.5 \%$ of cases the vein was three in number two in number in $35.5 \%$ cases, and in $50 \%$ cases it was one number.

According to Ankolekar vrinda $\mathrm{H}^{14}$ study PVLV was present in $89.1 \%$ of specimens.

\section{F) Marginal Vein of Left Ventricle}

1) Presence or absence of Marginal vein of left ventricle

In Ankolekar vrinda $\mathrm{H}^{14}$ found this vein in $78.1 \%$ of specimens.

R.Manoranjitham et $\mathrm{al}^{12}$ stated that marginal vein of left ventricle present in $93.33 \%$.

Malgorzata mazur et $\mathrm{al}^{13}$ corrosion casting study found this vein only in $11.25 \%$ of specimens.

\section{2) Comparison of number of marginal vein of} left ventricle

According to De Valle-Fernandez, this vein was three in number in $7 \%$,two in number in $37 \%$,one in number in $48 \%$, and absent in $7 \%$.

According to Ortale et al $^{11}$ the left marginal vein drained in to the GCV in $81 \%$ and in CS in $19 \%$ of specimens.

Malgorzata Mazur et $\mathrm{al}^{13}$ have indicated $98.75 \%$ specimens drained in to the GCV, and $1.25 \%$ in to the CS.

\section{Conclusion}

- Knowledge of the morphology of coronary sinus and its variations are useful for cardiologist and cardiothoracic surgeon for correctly interpreting angiographic data, stenting procedures and surgical myocardial revascularization. ${ }^{17}$

- There are numerous variations of the coronary sinus, coronary veins and its valves all of which may affect the degree of myocardial protection provided by retrograde cardioplegia.
- Coronary sinus anomalies has been recognized because of its relevance in interventional cardiology and also due to its association with other congenital cardiac defects

- The diameter of coronary sinus and Great Cardiac Vein will help cardiothoracic surgeons and interventional cardiologist to choose an appropriate sized catheter. The length of Coronary Sinus and Great Cardiac Vein will decide the catheter advancement.

- This study highlights the coronary venous anatomy and its variability in cardiac resynchronization therapy and electrophysiological studies. $^{21}$

- Thereby due to all these clinical significances, it is concluded that the information obtained from this study regarding the morphology of coronary sinus, will help to identify and to avoid potential complications during cardiac interventions.

\section{Bibliography}

1. Standring S. Gray's Anatomy, The Anatomical Basis of Clinical Practice. $40^{\text {th }}$ Edition, Churchil Living Stone; Elsevier, London,2008:981-982.

2. Sinnatamby. C.S, Last's Anatomy Regional and Applied, 11th Edition, Edinburg; Churchil Living Stone; 2006:206-213.

3. Snell. R.S, Clinical Anatomy by systems, Edition, Philadelphia, Williams and Wilkins; 2007:145-147.

4. Topal. E.J, Text book of interventional cardiology $5^{\text {th }}$ Edition, Philadelphia, Saunders, 2008;671-684.

5. A.K Dutta, Essentials of Human Anatomy (Thorax and Abdomen) $9^{\text {th }}$ Edition, Kolkata, Current books international ;2010:86-88.

6. Moore. K.L, Dalley, A.F, Clinically oriented Anatomy, $5^{\text {th }} \quad$ Edition, $P$ hiladelphia, Lippincott Williams \& Wilkins; 2006;159-162. 
7. Skandalakis. J.E, Surgical Anatomy ,The Embryological and Anatomic Basis of

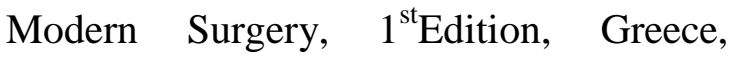
Paschalides Medical Publication; 2004; 305-07.

8. Francis-West. S.B.B, Larsen's Human Embryology, $4^{\text {th }}$ Edition, Churchil Livingstone; 2009;392-401.

9. Sadler, T.W, Langman's Medical Embryology, $11^{\text {th }}$ Edition, Lippincott Williams and Wilkins; 2010; 171-172, 192-195.

10. Cendrowska. M-Pinkosz, The variability of the Small Cardiac Vein in the Adult Human Heart, Folia Morphol, vol.63:No. 2, 159-162.

11. Ortale JR,Gabriel EA,Lost C,et al. The anatomy of the coronary sinus and its tributaries. Surg Radiol Anat 2001;23:1521.

12. R.Manoranjitham, R. Shalini, Suresh R. Gosai, C.Ravi Varman. Morphological Study of Coronary Sinus in Human Cadaveric Hearts. International Journal of Anatomy and Research, Int $\mathbf{J}$ Anat Res 2015, Vol 3(3):1415-18. ISSN 2321-4287.

13. Malgorzata Mazur, Mateusz Holda, Mateusz Koziej, Wieslawa KlimekPiotrowska, Marcin Kuniewicz, Aleksandra Matuszyk, Monika Konarska, Joanna Jaworek, Izabela Mroz. Morphology of tributaries of coronary sinus in humans-corrosion casting study. Folia Medica Cracoviensia Vol. LV, 2, 2015: 5-13.

14. Ankolekar Vrinda H, Quadros Lydia S \& D'souza Antony S. Morphometric and morphological variations of coronary venous system and its tributaries- An anatomical study. Journal of pharmacological and biomedical sciences ( $\mathrm{J}$ pharm Biomed Sci.)2013 September; 34(34): 1663-1669.
15. Von Ludinghausen M; Clinical anatomy of cardiac veins, Vv. Cardiacae. Surg Radiol Anat. 1987; 9 (2).Pp. 159-68.

16. Praveen I (2006) Great Cardiac Vein Draining Directly into The Right Atrium- A Case Report. J .Anat Soc India,55(2);60-64.

17. Lalit Mehra, Shashi Raheja, Sneh Agarwal, Yashoda Rani, Kulwinder Kaur, Anita Tuli. Anatomical Consideration and Potential Complications of Coronary Sinus Catheterisation. Journal of Clinical and Diagnostic Research.2016 Feb, Vol-10(2): AC12-AC15.

18. De Oliveria. I.M, Scanavacca, M.I,Correia, A.T, Sosa, E.A, Aiello. V.D, Anatomic Relations of the Marshall vein: Importance for Catheterization of the Coronary Sinus in Ablation Procedures, Europace J;2007;9:915-919.

19. Kavimani, Jebakani C.F. Coronary Sinus, World Journal of Medical sciences, 2014;10(1):61-64.

20. Bales GS;Great cardiac vein variations . Clin Anat.2005 May; 18(4);Pp.313.

21. Babak Payami, Akbar Shafiee, Maryam Shahrzad, Ali Kazemisaeed, Gholamreza Davoodi, Ahmad Yaminisharif. Posteroseptal accessory pathway in association with coronary sinus diverticulam: electrocardiographic description and result of catheter ablation. Interv Card Electrophysiol (2013)38;4349.

22. Moore K, Persaud T. Before We are Born: Essentials of Embryology and Birth Defects. $7^{\text {th }}$ ed. Philadelphia: Saunders Elsevier;2003.

23. Suma HY, Hariharan DR, Ramachandra Rao K. Coronary Venous Anatomy and its Relevance. International Journal of Anatomical Sciences 2013,4(2):14-19. 